\title{
THREE GALLS MADE BY CYCLORRHAPHOUS FLIES.
}

BY MILLETT T. THOMPSON, WORCESTER, MASS.

\section{Trypetidae.}

IN Aldrich's "Catalogue of North American Diptera" eight species of the Trypetidae are recorded as gall-makers; viz., Trypeta baccharis Coquillett, T. notata Coquillett, Ediaspis atra Loew, EE. polita Loew, Aciura aplopappi Coquillett, Eutreta diana Osten-Sacken, Eurosta bigloviae Cockerell, and E. solidaginis Fitch. More complete knowledge of the life-histories of this family will undoubtedly increase the list. In each case the gall is formed on some Composite plant, three of the above species - Ediaspis atra, E. polita and Eurosta solidaginis - attacking the genus Solidago. Material collected at Worcester Mass., during the past few months enables me to add Eurosta reticulata Snow, and Eutreta sparsa Wiedemann. Both make galls on the Golden-rod, and in this locality the galls have been found only on a large, smooth species, abundant in waste sandy fields, which I have not satisfactorily determined, perhaps Solidago juncea. But as these flies have a wide distribution, it is quite probable that other species also serve as the host-plant.

Eurosta reticulata (Figure 1). The gall is a hollow cylinder, about two centimeters long by a half centimeter in diameter, evidently an aborted and transformed growing-shoot. The tip of the gall projects above the surface of the ground. Externally, traces of leaves appear in the form of imbricated scales, the uppermost of which may - particularly as the Spring advances - spread apart and show considerable

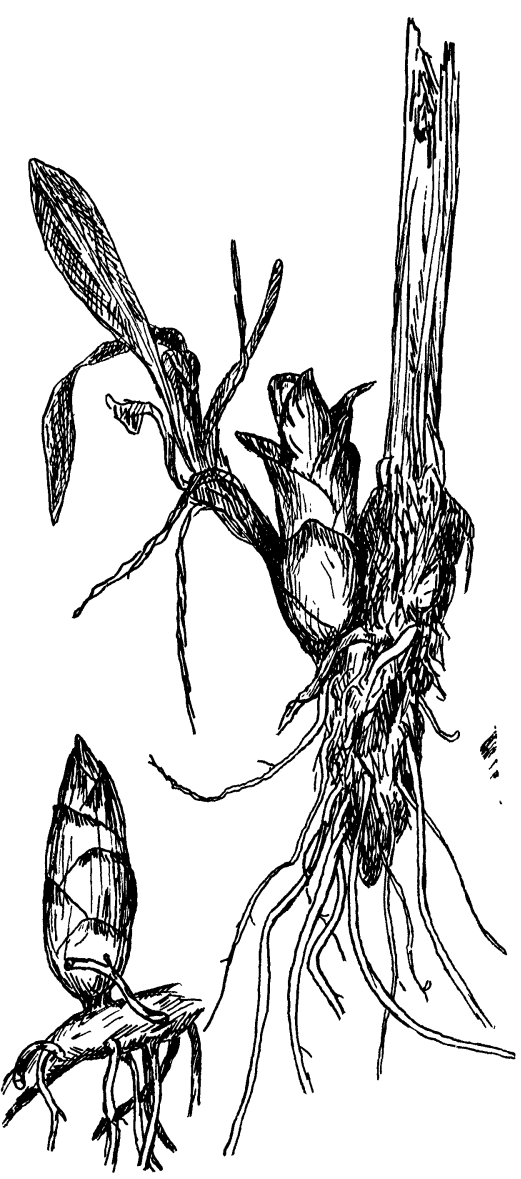

Figure 1, Gall of Eurosta reticulata. 
green color. Within is a large cavity, opening above between the closely appressed, scale-like leaves at the summit of the gall. The walls of the gall are moderately thick, fleshy, and firm.

I first discovered these galls in the latter part of April, but even at that date the pupal stage had been attained. The formation of the gall and the growth of the larva must take place during the previous Fall, while the shoot is still very imma-

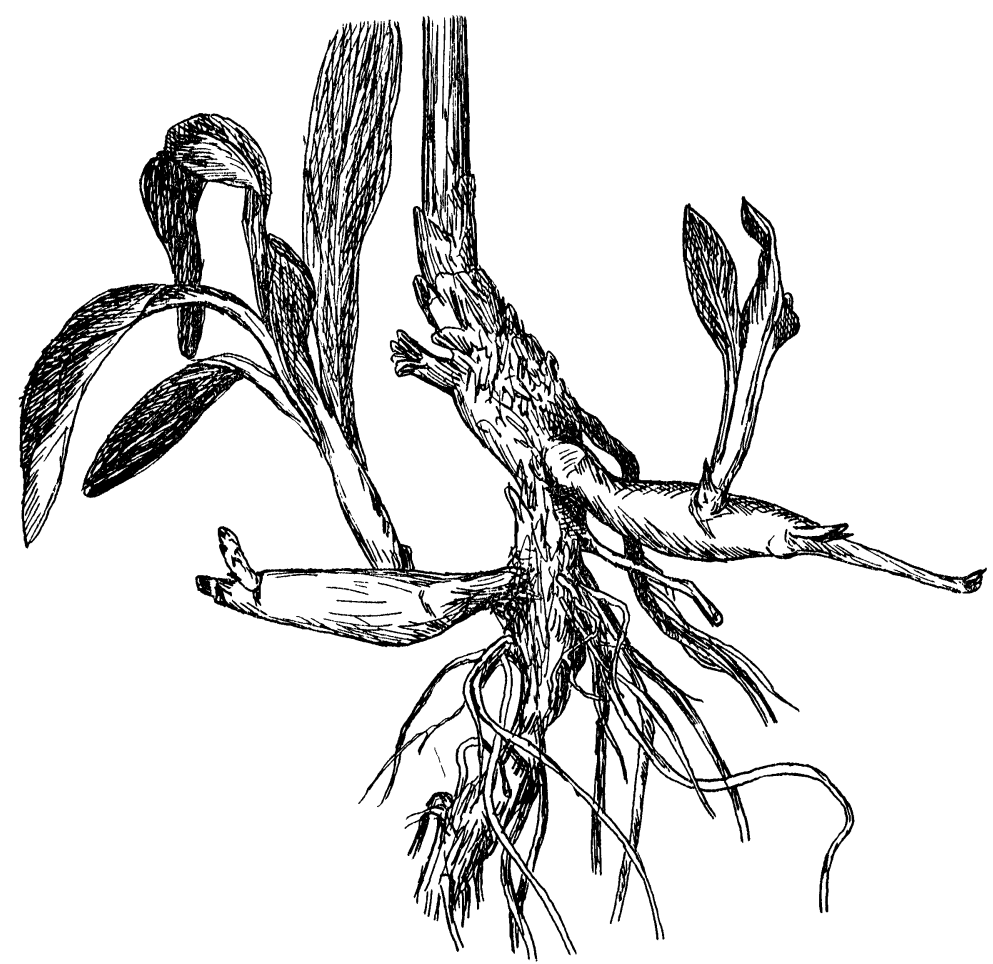

Figure 2, Galls of Eutreta sparsa.

ture. In each gall the puparium lay in the upper part of the chamber. The flies emerged the last week in May and the first week in June. Many of the galls were parasitized by a large black Chalcis-fly.

Eutreta sparsa (Figure 2). While the gall of Eurosta reticulata projects above the surface of the ground, the gall of the present species is wholly underground. The injury here is likewise to the young shoots, but the gall is less specialized and 


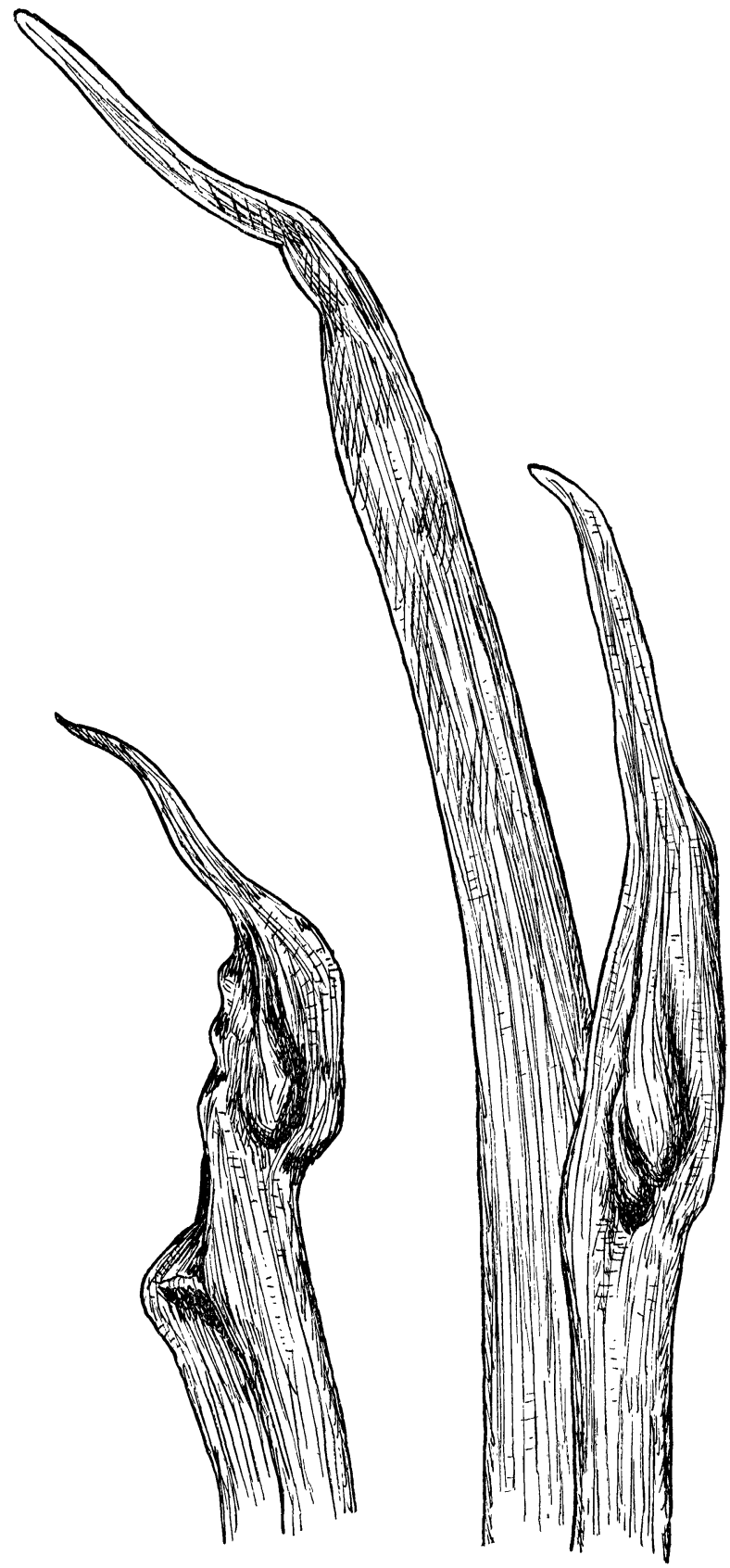

Figure 3, Gall of Agromyza magnicornis. 
further growth of the shoot is not absolutely prevented. The gall indeed lies near the border-line between a true gall and such pseudo-galls as wood-inhabiting beetle larvae produce when boring in slender twigs. The larval chamber is small and irregular in form. Typically, the shoot swells and becomes a hollow, long-oval gall such as is shown in the figure. All forward growth of the shoot as a whole is stopped, but lateral reserve buds may grow and develop leaf rosettes. More rarely, only the proximal end of the shoot is affected, forming a short-oval or globular gall and the terminal bud develops normally. The long-oval galls usually measure 2 or 3 centimeters.

In April the gall of Eutreta sparsa was found to be of full size, but the contained larva was still small. The larva grew rapidly during May and pupated early in June. This stage lasted a little over two weeks, the flies emerging about the 20th of the month.

\section{Agromyzidan.}

Agromyza magnicornis Loew. (Figure 3). When the leaves of the Blue Flag, Tris, are a few inches tall, the outermost leaf of the leaf-bundle is often found to be modified in so definite a manner that the resulting structure can be called a "gall." The leaf ceases to grow. The upper part broadens and also becomes thickened over a limited area, so that there is a very characteristic bulge on either side of the blade. If this be cut into,- even early in the Spring,- - a small, oval, laterally compressed puparium is found. The flies emerge from these puparia about the last of May. This, I believe, is the first gall-like structure to be described for an Agromyzid, though the point of attack, the leaf, agrees well with the habits of other members of the Family, many of which mine the foliage of plants. As in the Trypetid galls already described it seems here that the larval life is completed during the previous Fall. But I have not as yet obtained data on this point.

The alteration of the outer leaf not infrequently injures the inner or second leaf of the leaf-bundle in a conspicuous way. The tip of the latter becomes caught in the malformed groove of the outer leaf and is held fast for a longer or shorter period. As a result the rapidly growing leaf is bent, and although it ultimately becomes free, yet the twisting produces a noticeable series of wavy folds.

I am indebted to Mr. C. W. Johnson of the Boston society of natural history for identification of the Trypetids and to Mr. D. W. Coquillett for that of the Agromyza.

Clark University, Worcester, Mass. 

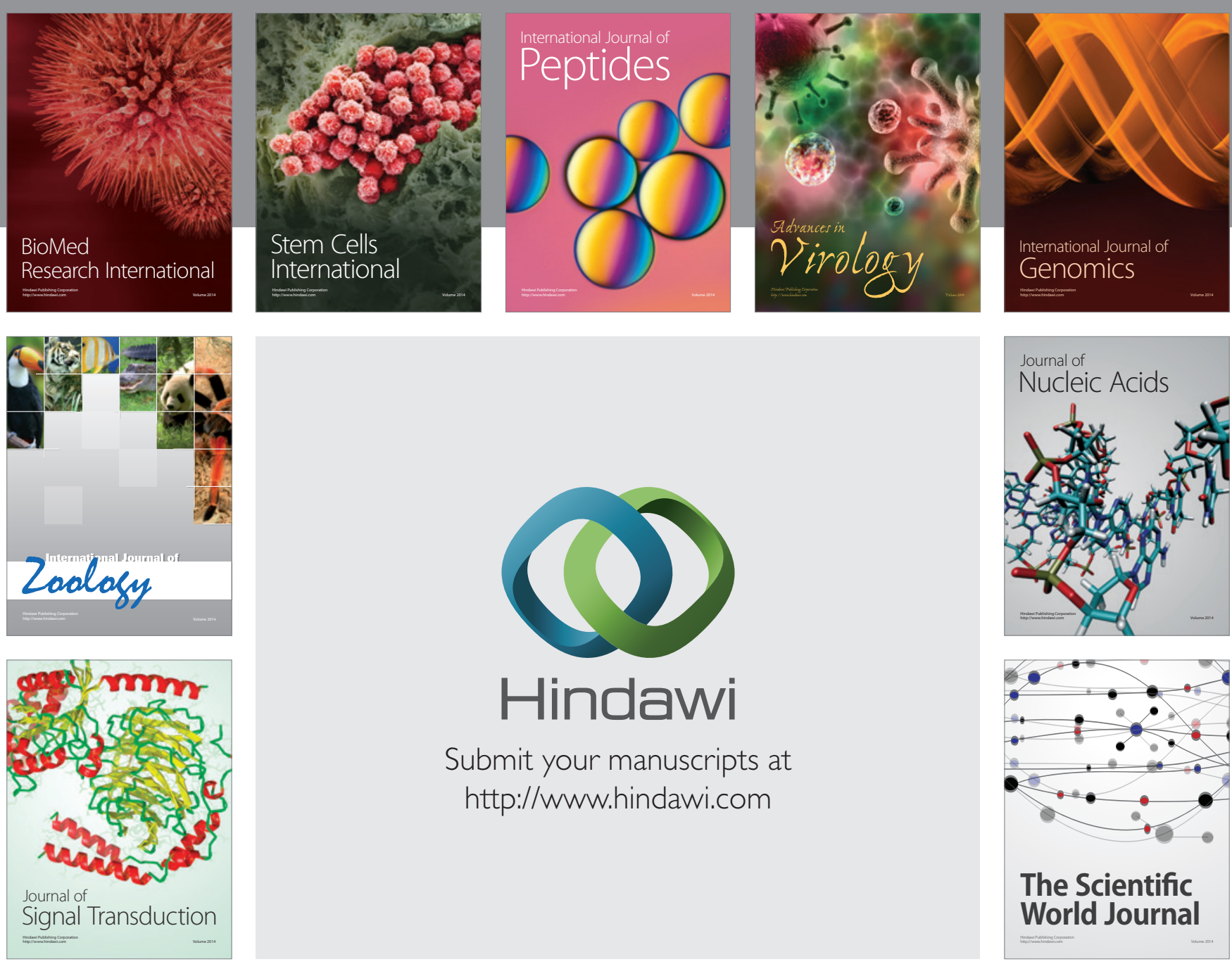

Submit your manuscripts at

http://www.hindawi.com
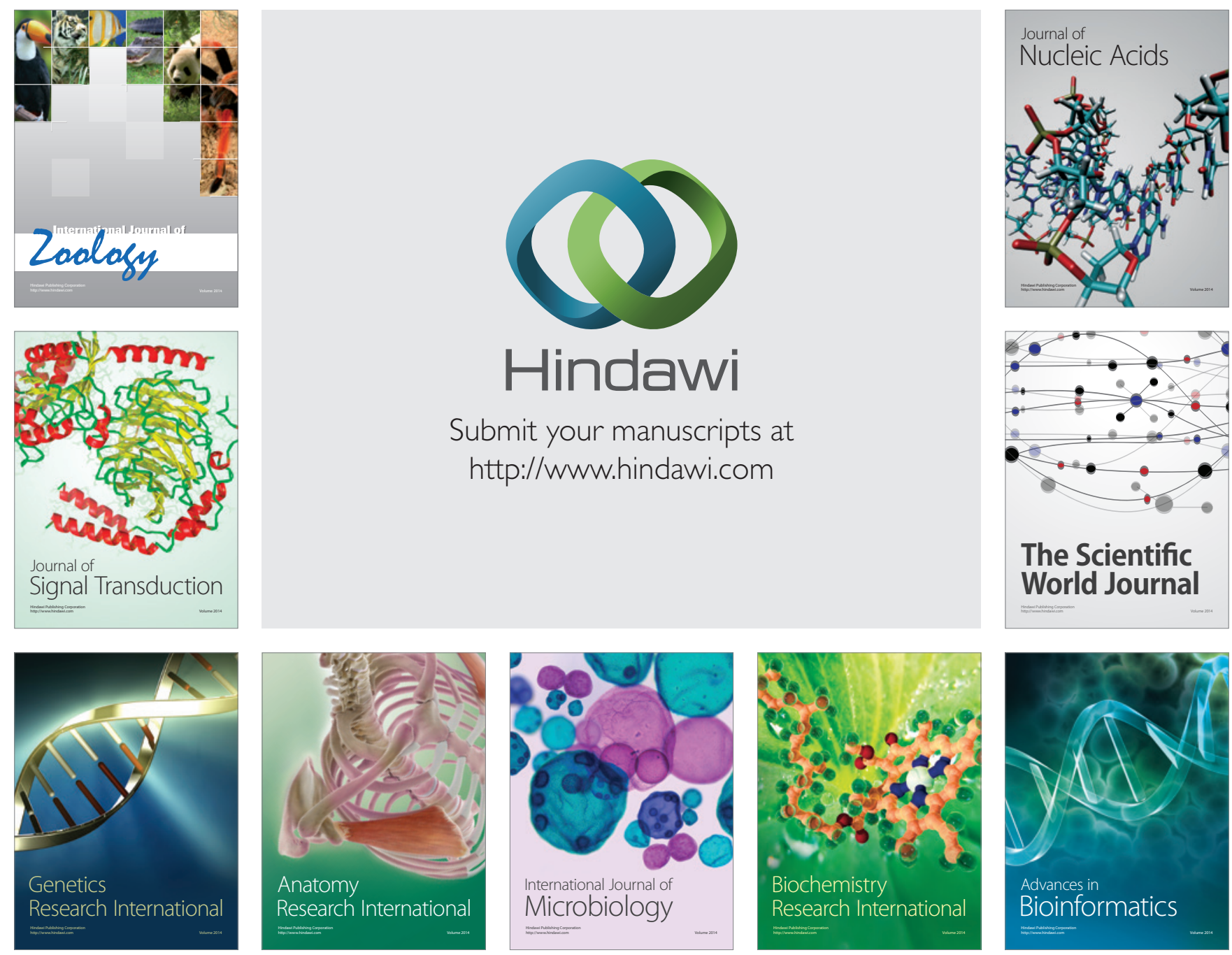

The Scientific World Journal
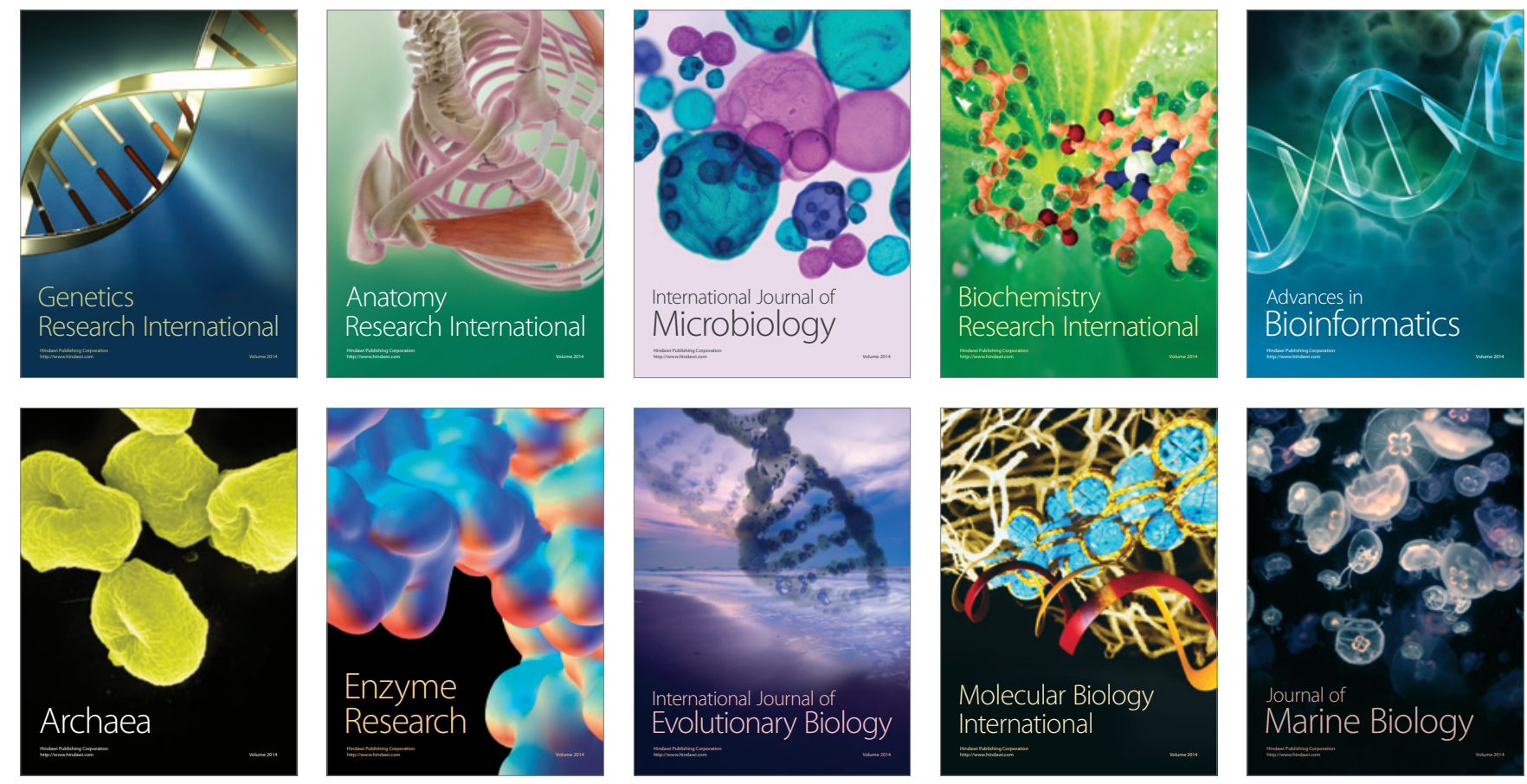